\title{
Analytical and phytochemical exploration of the seeds of Annona Squamosa
}

\begin{abstract}
Natural product chemistry has contributed significantly towards the development of modern medicine. The following paper deals with the phytochemical screening and detection of steroidal glycosides in the ethanolic extract of Annona squamosa seeds. This study involves preliminary screening, detection and thin layer chromatography and column chromatography separation of secondary metabolites from the seed extract of Annona squamosa Linn. Further, absorbance studied by Ultraviolet spectroscopy and HPLC detection followed by functional group detection by FTIR and proton studied by PNMR had been studied. A potent bufadenolide has been isolated from the seeds of Annona squamosal. The generated data has provided the basis of its wide use as therapeutantin traditional and folk medicines.
\end{abstract}

Keywords: phytochemical, annona, shinoda, squamosal, bufadienolide, annona squamosal, chromatography
Volume 3 Issue 4 - 2016

\author{
Saptarshi Das,' Anshuman Bhattacharya,' \\ Biswanath Ghosh,' Himangshu Shekar Maji ${ }^{2}$ \\ IWest Bengal University, India \\ ${ }^{2}$ Department of Pharmaceutical Science and Technology, JIS \\ University, India
}

Correspondence: Himangshu Sekhar Maji, Professor, JIS University, 8I, Nilgunj Road, Agarpara, Kolkata, 700109, West Bengal, India,Tel 9433 I45025, Email hsmaji77@gmail.com

Received: October 31, 2016 | Published: November 15, 2016
Abbreviations: IP, internet protocol; TLC, thin layer chromatography; UV, ultraviolet; Rf, radio frequency; HPLC, high performance liquid chromatography; NMR, nuclear magnetic resonance

\section{Introduction}

Natural remedies from medicinal plants are found to be safe and effective. Many plant species have been used in folkloric medicine to treat various elements. Even today compounds from plants continue to play a major role in primary health care as therapeutic remedies in many developing countries. Plants are a rich source of secondary metabolites with interesting biological activities. In general, these secondary metabolites are an important source with a variety of structural arrangements and properties. ${ }^{1}$ Distinguished examples of these compounds include flavonoids, phenols, phenolic glycosides, saponins and cyanogenic glycosides.,3 Natural products from microbial sources have been the primary source of antibiotics, but with the increasing recognition of herbal medicine as an alternative form of health care, the screening of medicinal plants for active compounds has become very significant because these may serve as sources of antibiotic prototypes. ${ }^{4,5}$ It has been shown that in vitro screening methods could provide the needed preliminary observations necessary to select crude plant extracts with potentially useful properties for further chemical and pharmacological investigations. ${ }^{6}$ Annona squamosa Linn. (Family; Annonaceae) commonly known as custard apple, is a woody, semi deciduous tree grown throughout India in rocky terrain with shallow and well drained soils. A bark decoction of this plant is used to prevent diarrhea, while the root is used in the treatment of dysentery.

Collectively plants synthesize a diverse carry of secondary metabolites, either as part of normal. Growth and development or in response to, pathogen attack or stress. By definition, secondary metabolites are regarded as "Luxury item" that are not required for growth and reproduction of plant, at least under defined condition. Since the ability synthesize particular classes of secondary metabolites is restricted to certain plant groups, this compounds are clearly not essential for survival. However they may be important in conferring selective advantages, for example by suppressing the growth of neighboring plants or by protecting against pests, pathogens and stress. They may also have physiological roles in plants, which are as yet uncharacterized. In addition to their natural roles in plants secondary metabolites also represent a vast resource of complex molecules that are valued and exploited by man for their pharmacological and other properties.

Annona squamosa, the sugar-apple, sweetsop, or sugar-pineapple, is a species in the Annonaceae family that is native to the tropical Americas and widely grown for its fragrant, juicy, and flavorful fruit, which contains more vitamin $\mathrm{C}$ than an orange. Most widely cultivated of tropical fruits in the family, which includes cherimoya (A. cherimola), sugar-apple (A. squamosa), and paw (Asiminatriloba).

Distributed in lowland tropical climates worldwide, including in southern Mexico, the Antilles, and Central and South America, tropical Africa, Australia, Indonesia, Polynesia, and, in the U.S., in Hawaii and Florida. It was introduced to India and the Philippines by the Spanish and Portuguese in the 16th century, and has been cultivated there ever since. Its native range is not known due to extensive cultivation and naturalization, but is thought to have originated in the West Indies, and was first described from Jamaica. It is naturalized north to southern Florida in the United States and south to Bahia in Brazil, and in many parts of Asia, and is considered invasive in French Polynesia and several Pacific islands.

Annona is a cold-intolerant, semi-evergreen shrub or small tree reaching 8 meters $(26 \mathrm{ft}$ ), one of the smaller members of its genus. Trees may flower and bear fruit starting at 2-3 years of age. Fruit production can be prolific with adequate precipitation $(>70 \mathrm{~cm}$ or 27 inches per year), but in non-native ranges is often limited by absence of native pollinators, which include various beetle species; flowers are too deep to be readily pollinated by honeybees (Apismellifera). Hand pollination is used to increase yields.

The compound fruits are round to oblong, 6-10 $\mathrm{cm}(2.4-3.9$ in) diameter, with a thick, scaly or knobby skin that gives them a pinecone appearance. Fruits weigh 100-230g (3.5-8.1oz). The fruit flesh is fragrant, sweet, and white to light yellow, with the texture and flavor 
of custard; the flavor is considered the best among fruits in the genus. Fruits are divided into 20-38 segments, each generally containing a hard, shiny brownish-black, seed, enmeshed in the flesh, although some trees produce seedless fruit ${ }^{7}$ The fruits are generally eaten fresh, or used to make juice beverages or sorbet, and are a good source of iron, calcium, and phosphorus.

The seeds are toxic, and have been used as an insecticide and to treat head lice (although the preparation is an eye-irritant and can cause blindness). Seeds are, however, high in oil, which can be used in soap manufacture or, if treated to remove the toxic alkaloids, as a cooking oil. Leaves, unripe fruits, and extracts of bark and root, all rather astringent, have been used in traditional medicine to treat fevers, rheumatism, diarrhea, dysentery, and other ailments. The aromatic leaves are occasionally used in perfumes, and fibers from the bark are used to make cords and ropes. Annona squamosa has been found to possess antidiabetic, ${ }^{8}$ abortificant ${ }^{9}$ antimicrobial, ${ }^{10-12}$ antitumor ${ }^{13}$ and antioxidant ${ }^{14}$ and larvicida ${ }^{15}$ properties. The oral acute toxicity study of Annona squamosa leaves were studied and it has been reported ${ }^{16}$ to be safe up to $1500 \mathrm{mg}$ per kg body weight for ethanol-water fraction and up to $3000 \mathrm{mg}$ per $\mathrm{kg}$ body weight for petroleum ether fraction.

\section{Materials and methods}

\section{Phytochemical analysis of seed extract}

\section{Test for flavonoids}

a. Shinoda test: To the test solution add few magnesium turnings and concentrated hydrochloric acid drop wise, pink scrale, crimson red or occasionally green to blue color appears few minutes.

b. Alkaline reagent test: To the solution add few drops of sodium hydroxide solution, intense yellow color is formed which turns to colorless on addition of few drops of dilute acid indicate presence of flavonoids.

\section{Test for tannins}

a. Ferric chloride test: Treat the extract with ferric chloride solution, blue color appears if hydrolysable tannins are present and green color appears if condensed tannins are present.

b. Gelatin test: To the test solution add 1\% gelatine solution containing $10 \%$ sodium chloride. Precipitate is formed.

\section{Test for cardiac glycosides}

a. Keller- killani test: $5 \mathrm{ml}$. of the extract sample dissolve in $5 \mathrm{ml}$. of water. Add $2 \mathrm{ml}$. glacial acetic acid with $3 \mathrm{ml}$. ferric chloride solution; further add 6 drops concentrated sulphuric acid. A brown ring will be observed in the solution.

b. Raymonds's test: Extract solution treat with hot methanolic alkali, a deep violet color occurs.

c. Baljet's test: To the extract add few ml. of picric acid solution (IP), an orange color is formed.

\section{Test for saponin glycosides}

a. Foam test: $2 \mathrm{ml}$. solution of extract are taken in a test tube with water, shake well vigorously. Foam will produce in the upper layer of the solution.

\section{Test for steroids}

a. Salkowski test: $5 \mathrm{ml}$. extract solution was mixed with few $\mathrm{ml}$. of chloroform and shaken with concentrated sulphuric acid. After standing some time it yields red color.

b. Liberman- buechardt test: Extract solution treat with few ml. acetic anhydride and $1 \mathrm{ml}$. of concentrated sulphuric acid. Stand for few minutes. It gives reddish ring at junction of two layers of the solution.

\section{Test for alkaloids}

a. Mayer's reagent test: Alkaloids give cream color precipitate with Mayer's reagent (i.e. potassium mercuric iodide solution).

b. Wagner's reagent test: Alkaloids reddish brown precipitate with wagner's reagent (i.e. iodine-potassium iodide solution).

c. Hager's test: Alkaloids give yellow precipitate with Hager's reagent (Saturated solution of picric acid).

\section{Preparation of saturated solution of picric acid I \% w/v solution}

$100 \mathrm{ml}$ water mixed with $1 \mathrm{gm}$ of picric acid thoroughly, solution mixed with extract solution heat slidely a yellow precipitate was present.

a. Dragendroff's test: - Alkaloids give reddish brown precipitate with Dragendroff's reagent. ( i.e. potassium bismuth iodine solution).

\section{Preparation of potassium bismuth iodide solution}

a. Step 1: Solution 1-0.85gm of potassium iodide mix with $10 \mathrm{ml}$ of glacial acetic acid and $40 \mathrm{ml}$ of water. Heat and filter. Solution 2- Dissolve potassium iodide in $30 \mathrm{ml}$ water.

b. Step 2: Stock preparation $=$ Solution $1+$ Solution 2.

\section{Separation of secondary metabolites of ethanolic extract by thin layer chromatography}

a. Step1: Preparation the developing container: The developing container for TLC can be a specially designed chamber, a beaker with a watch glass on the top. Pour solvent into the chamber to the depth of just less than $0.5 \mathrm{~cm}$. To aid in the saturation of the TLC chamber with solvent vapour, and can be line part of the inside of the beaker with filter paper. Cover the beaker with a watch glass, swirl it gently, and allow to stand while prepare the TLC plate.

b. Step2: Preparation the TLC plate: Glass plates are of specific dimensions like $20 \mathrm{~cm} \times 20 \mathrm{~cm}$ (full plate) $20 \mathrm{~cm} \times 10 \mathrm{~cm}$ (half plate) and $20 \mathrm{~cm} \times 5 \mathrm{~cm}$ (quarter plate) can be used. The slurry, which is a mixture of stationary phase and water, is prepared by using a specific ratio (here Silica gel $\mathrm{G}$ is used as stationary phase, and the ratio with water is, Silica gel G: water (5.5: 10). After preparing the slurry, the TLC plates are prepared by using spreading technique. It is the best technique where the thickness of the adsorbent layer is uniformly adjusted. The plates are allowed for setting (air drying) to avoid cracks on the surface of adsorbent. After setting, the plates are activated by keeping in an oven at $100^{\circ} \mathrm{C}$ to $120^{\circ} \mathrm{C}$ for 1 hour, this is for nothing but removing the water/moisture and other absorbed substances from the surface of any absorbent.

c. Step 3: Spot the TLC plate: The test sample is spotted by using a capillary tube. The spot should be kept at least $2 \mathrm{~cm}$ above the base of the plate and the spotting area should not be immersed in the mobile phase in development tank. 
d. Step 4: Develop the plate: Place the prepared TLC plates in the developing beaker, cover beaker with the watch glass, and leave it undisturbed. The solvent will rise up the TLC plate by capillary action. Make sure the solvent does not cover the spot. Allow the plate to develop until the solvent is about half centimeter below the top of the plate. Remove the plate from the beaker and allow the plate to air dry.

e. Step 5: Visualize the spots: If there are any colored spots, circle them lightly with pencil, Most samples are not colored and need to be visualized with a UV lamp $(275 \mathrm{~nm})$. Keeps the plates in a UV chamber, and mark the distance travelled by the solute and distance travelled by the solvent front, and then calculate the Rf value. Rf value is the ratio of distance travelled but the solute and the distance travelled by the solvent front.

\section{Separation of secondary metabolites of ethanolic} extract by column chromatography

I. Packing of column: A $50 \mathrm{ml}$ burette will be modified for use as a chromatography column. Place a small plug of cotton at the bottom of burette. The column is packed by Silica Gel GF, which is first made slurry with the solvents selected in thin layer chromatography, (i.e., n-butanol : glacial acetic acid: water: $70: 25: 5)$. Then the slurry is poured in the column very carefully because there should be chance of air bubble during packing, which leads to the crack of the column. When the slurry is settled down then the solvent is allowed to run down until the liquid level is about $1 \mathrm{~cm}$ above the top level of the column. The liquid level should never fall off below the adsorbent otherwise cracks will be developed and column becomes useless.

II. Load the sample in column: The extract is first mixed with solvent to make a mixture and gently transferred to the top of the column, without disturbing the Silica Gel surface (best accomplished using a pipette to drip it down the inside wall to the top of the Silica Gel). Open the stop cork to let the extract go into the Silica Gel (once again not allowing the Silica Gel to go dry). Add $1 \mathrm{ml}$ or $2 \mathrm{ml}$ of eluent, and open the stop cork to load this also (pushing the extract further down the column).

III. Column chromatography-collecting fraction: Gently add additional solvent until the column is filled. Open the stop cork to let solvent flow through. The first $10 \mathrm{ml}$ can be collected in a beaker. After the initial $5 \mathrm{ml}$, collected in test tubes with about 10 $\mathrm{ml}$ in each tube. Add more fresh solvent to the top of the burette as needed. Collect at least 20 fractions to ensure that have collected all of the desired compounds.

IV. Analysis the fractions absorbance by Ultraviolet Spectroscopy: The fractions are thus scanned in UV spectrophotometer (Schimadzu 1800 series) to determine $\lambda \mathbf{m a x}$. Ultraviolet spectroscopy is concerned with the study of absorption of UV radiation which ranges from $200 \mathrm{~nm}-800 \mathrm{~nm}$. Compounds which are coloured absorb radiation from $400 \mathrm{~nm}$. But compounds which are colourless absorb radiation in the UV region. IN both UV as well as visible spectroscopy, only the valence electron absorb the energy, thereby the molecule undergoes transition from ground state to excited state. This absorption is characteristic and depends on the nature of electrons present. The intensity of absorption depends on the concentration and path length as given by Bee-Lambert's law.

Fraction samples were scanned under 400-200nm wavelength to get their $\lambda \max$. Samples having identical absorption maxima are pooled together and concentrated for further studies.

\section{HPLC study of the concentrated sample obtained from column chromatography}

\section{a. Chromatographic conditions}

Instrument used - Agilent 1260 Infinity series HPLC isocratic

Mobile phase used - Acetonitrile : water (80:20)

Column used - Agilent C18 column

Detector used - UV detector at $\lambda \max 281 \mathrm{~nm}$.

Room temperature - 250C. $\pm 40 \mathrm{C}$.

The separation was performed using isocratic elution ( $0-10 \mathrm{~min})$ with a flow rate $1.0 \mathrm{ml} / \mathrm{min}$ and a column temperature $20^{\circ} \mathrm{C}$. The injection volume was $20 \mu \mathrm{l}$, and UV detection at $281 \mathrm{~nm}$. HPLC grade solvents were obtain from Merck chemicals ltd. After phytochemical studies of ethanolic extract $(10 \mu \mathrm{g} / \mathrm{ml})$ were subjected to HPLC column and obtained record were superimposed on retention time values of these extract.

\section{Infrared spectroscopy study of the ethanolic extract}

Every bond or proton of a molecule or functional group requires different frequency for absorption. hence characteristics peak is observed for every functional group or part of the molecule. In others words IR spectra is nothing but a finger print of a molecule. In pharmaceutical analysis, we use infrared radiation (mid- IR) of wavelength $25 \mu$ to $2.5 \mu$ or wave numbers from $600 \mathrm{~cm}-1$ to $4000 \mathrm{~cm}-1$.

Concentrated semisolid sample were mixed with potassium bromide for pellet formation. Then the pellet were placed in FTIR for determination its functional groups. After background measure with pure $\mathrm{KBr}$ pellet sample pellet scanned for 24 times.

a. Instrument used: Bruker'salpha FTIR system with OPUS version 7.0.122 in Bengal School of Technology.

\section{Proton magnetic resonance study of ethanolic extract}

Any proton or nucleus with odd mass number spins on its own axis. By the application of an external magnetic field (Ho), the nucleus spins on its own axis and a magnetic moment is created, resulting in a precessional orbit, with a frequency called as precessional frequency. This state is called as Ground State or Parallel orientation. In this state the magnetic field caused by this spin of nuclei is aligned with the externally applied magnetic field. When energy in the form of Radiofrequency is applied and when Applied frequency = Precessional frequency, absorption of energy occurs and a NMR signal is recorded.

\section{Result and discussion}

Phytochemical screening result is shown in Table 1. Percentage yield of crude extract of petroleum ether extract and Ethanol extract were $78.52 \%$ and $89.93 \%$ respectively. Considering the polar nature of active phytoconstituent, the ethanol extract was more preferable for the further experiment. In the thin layer chromatography using mobile phase ethyl acetate methanol water in ratio of 100: 13.5: 10 the retention factor $(\mathrm{R} f)$ of the ethanolic extract was 0.90. (i.e. mentioned mobile phase composition was used for better separation of steroidal or cardiac glycoside). HPLC data (Figure 1) shows that in retention time 2.272 minutes, a single peak shows the presence of a single compound in the isolated ethanolic extract of Annona squamosa seed. 
From the IR spectra (Figure 2), It can be concluded that, transmittance at $3628 \mathrm{~cm}-1$ is due to $-\mathrm{OH}$ stretching, transmittance at $2921 \mathrm{~cm}-1$ is due to $-\mathrm{CH}$ stretching, transmittance at $1737 \mathrm{~cm}-1$ is due to $>\mathrm{C}=\mathrm{O}$ stretching. The compound, can be concluded to contain an alkyl group (-CH3) group, hydroxyl $(\mathrm{O}-\mathrm{H})$ group and a carboxyl $(\mathrm{C}=\mathrm{O})$ group. From the $1 \mathrm{H}$ NMR spectra (Figure 3 ). It can be concluded that, Chemical shift value at 0.8 , is due to a primary proton. Chemical shift value at 1.38 is due to a secondary proton, Chemical shift value at 1.5 is due to a tertiary proton, Chemical shift value at $3.6-3.5$ is due to ester / ether linkage, Chemical shift value at 2-2.7 is due to carboxyl group, Chemical shift value at 6-7 is due to an aromatic ring, Chemical shift value at $4.6-5.9$, is due to vinylic carbon. $(\mathrm{C}=\mathrm{C}-\mathrm{H})$. The compound can be concluded to contain a primary proton, two secondary protons, two tertiary protons, an ester /ether linkage five carboxyl groups, an aromatic ring, and two vinylic carbons.

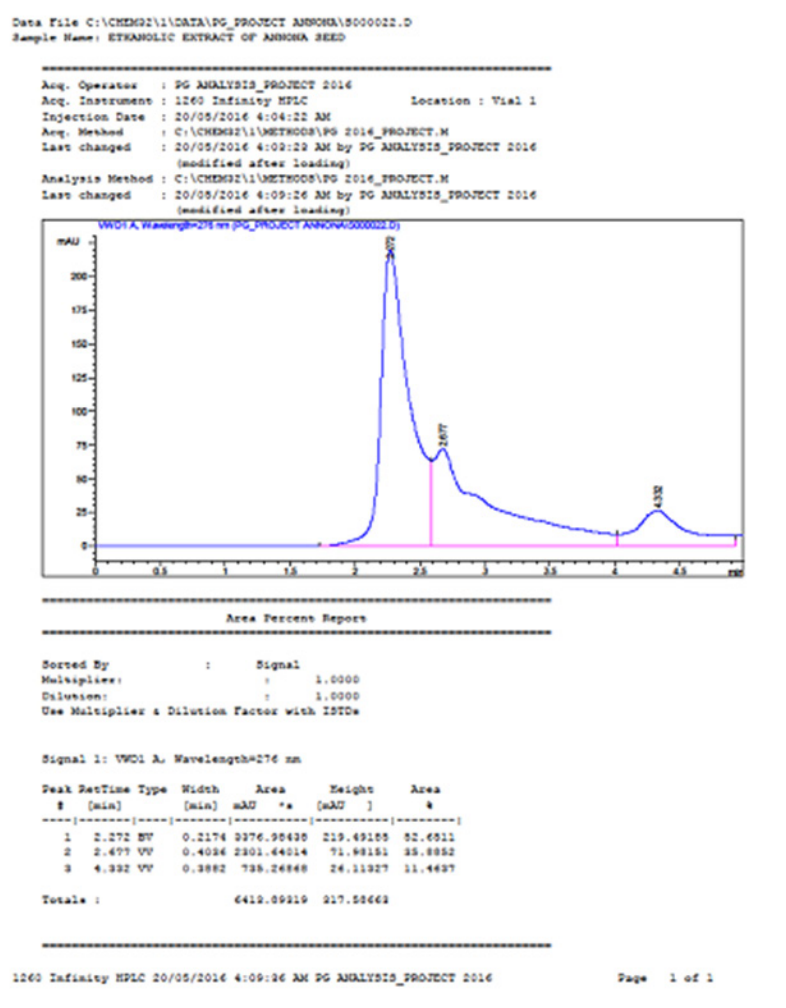

Figure I HPLC spectrum of the seeds of Annona squamosa.

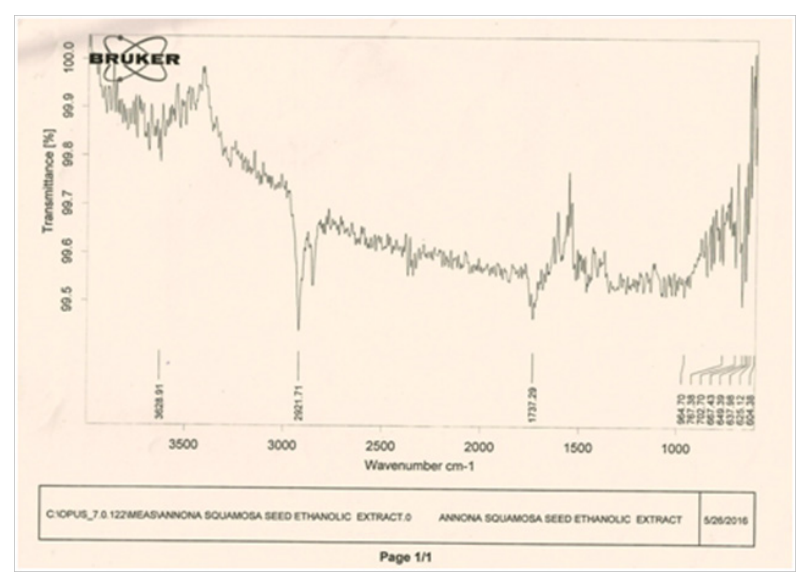

Figure 2 FTIR spectrum of the seeds of Annona squamosa.

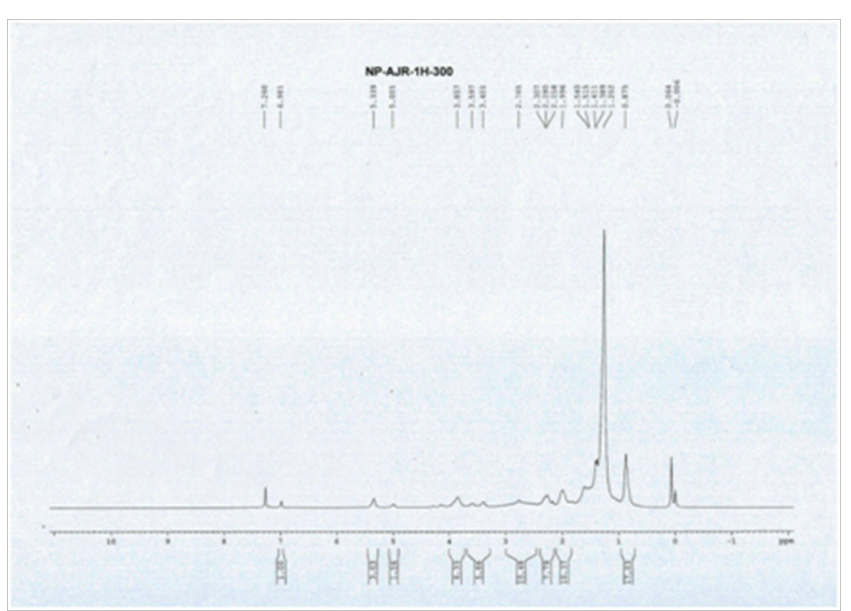

Figure 3 Proton NMR spectrum of the seeds of Annona squamosa.

Table I Phytochemical screening of Extracts of Annona squamosa seed

\begin{tabular}{llll}
\hline Test for & Test performed & $\begin{array}{l}\text { Pet. ether } \\
\text { extract }\end{array}$ & $\begin{array}{l}\text { Ethanol } \\
\text { extract }\end{array}$ \\
\hline \multirow{2}{*}{ Alkaloid } & Draggendroff's test & - & + \\
& Hager's test & - & + \\
\multirow{2}{*}{ Cardiac glycoside } & Keller Kiliani test & - & + \\
& Raymond's test & - & + \\
\multirow{2}{*}{ Saponin glycoside } & Baljet's test & - & + \\
\multirow{2}{*}{ Steroid } & Foam test & + & + \\
& Salkowski test & + & + \\
\multirow{2}{*}{ Tannin } & Libermann-Buchardt test & + & + \\
& Ferric chloride test & + & - \\
\hline
\end{tabular}

\section{Conclusion}

This report describes their isolation and characterization was obtained as colourless plate $(\mathrm{C} 2 \mathrm{H} 5 \mathrm{OH})$, and positive to LibermanBurchard reaction. The UV $(295 \mathrm{~nm})$ and IR absorption spectra suggested the presence of 2-pyrone ring $(1635 \mathrm{~cm}-1)$ and ketone group (1712 cm-1). In the $1 \mathrm{H}$ NMR spectrums, signals at 7.26 , and 6.98) were characteristic of the 2-pyrone ring may of bufadienolide. All the information above showed that compound was may be a bufadienolide. From the UV spectrometry scan, HPLC data curve peak, 1H NMR spectra, IR spectra, the possible structure of the compounds is as follows, which similar to a cardiac glycoside, further test and elaboration will continued.

\section{Acknowledgements}

The author wish to thank the management of Bengal School of Technology for providing the necessary infrastructure and facility to carry out the research work.

\section{Conflicts of interest}

The author declares that he does not have any financial and other conflict of interest in publishing the manuscript.

\section{Funding}

None. 


\section{References}

1. de-Fatima A, Modolo LV, Conegero LS, et al. Lactones and their derivatives:biological activities, mechanisms of action and potential leads for drug design. Curr Med Chem. 2006;13(28):3371-3384.

2. Shahidi F. Antioxidant factors in plant foods and selected oilseeds. BioFactors. 2000;13(1-4):179-185.

3. Shahidi F, McDonald J, Chandrasekara A, et al. Phytochemicals of foods, beverages and fruit vinegars:chemistry and health effects. Asia Pacific J Clin Nutr. 2008;17(1):380-382.

4. Grimes MB, Mcbeth DL, Hallihan B, et al. Antimicrobial activity in medicinal plants of the Scrophulariaceae and Acanthaceae. Int $J$ Pharmacognosy. 1996;34(4):243-248.

5. Koduru S, Grierson DS, Afolayan AJ. Antimicrobial activity of Solanumaculeastrum. Pharm Biol. 2006;44(4):283-286.

6. Mathekaga AD, Meyer JJM. Antibacterial activity of South African Helichrysum species. South African Journal of Botany. 1998;64(5):293-295.

7. Morton, Julia F. Soursop Annona muricata. Fruits of warm climates, 1987. p. 75-80.

8. Ranveer ST, Siddharaj SS. Antidiabetic Activity of Annona squamosaL. In Experimental Induced Diabetic Rats. International Journal of Pharmaceutical \& Biological Archives. 2012;3(6):1492-1495.

9. Mishar A, Dogra JV, Singh JN, et al. Planta Medica. 1979;35(3):283285.
10. Jain GC, Dixit VP. Effect of Annona squamosa EtOH extract and testicular function of dogs (Canisindicus Linn.). II Annual Session of Science. 1982. 22 p.

11. Patel DJ, Vipin K. Annona squamosa L.:Phytochemical analysis and Antimicrobial Screening. Journal of pharmacy research. 2008;1(1):3438.

12. Vidyasagar GM, Singh SP. A comparative Antimicrobial activity of methanolic root, leaf, seed cotyledon extracts of Annonasquamosa L. International Journal of Pharmacy and Pharmaceutical Sciences. 2012;4(5)

13. Khar A, Pardhasaradhi BVV, Madhurima R, et al. Antitumour activity of Annonasquamosa seed extracts is through the generation of free radical $\mathrm{s}$ and induction of apoptosis. Indian $J$ Biochem Biophys. 2004;41(4):167-172.

14. Kothari V, Seshadri S. Antioxidant activity of seed extracts of Annona squamosaand Carica papaya. Nutrition \& Food Science. 2010;40(4):403-408.

15. Rodrigues AMS, De Paula JE, Degallier N, et al. larvicidal activity of some cerrado plant extracts against Aedesaegypti. J Am Mosquito Control Asso. 2006;22(2):314-317.

16. Pax JM, Ester I, Baraka S. Oral acute toxicity study of Annona squamosa 1. Leaves extract and fractions in albino mice. Journal of Advanced Scientific Research. 2016;7(1):38-42. 